Antihyperglycemic activity of fruit extracts of Sri Lankan endemic species Garcinia quaesita Pierre "Rathgoraka" and its isolated compound, garcinol

D.S.N.K. Liyanagamage, S. Jayasinghe, A.P. Attanayake, V. Karunaratne and D.S.A.Wijesundara

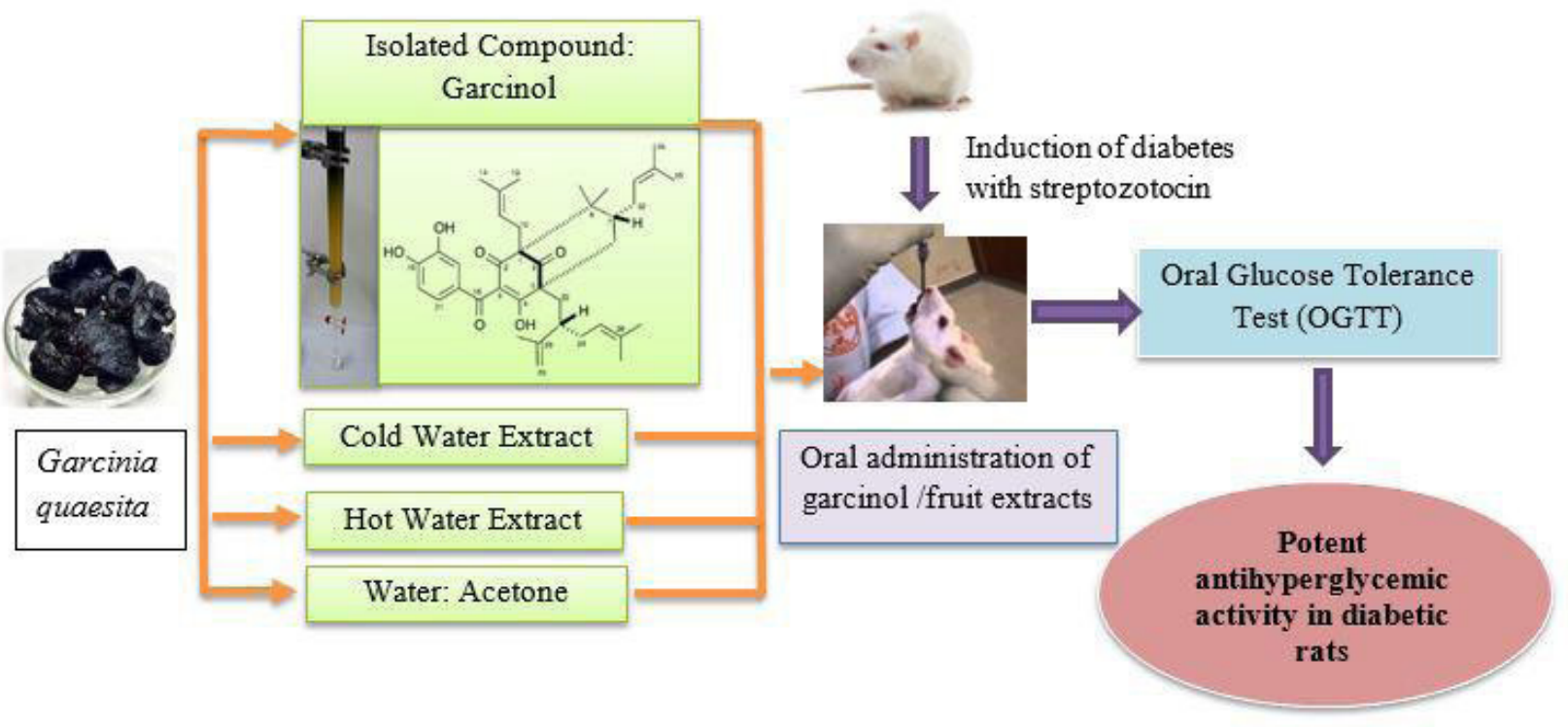

\title{
Highlights
}

- Crude extracts of G. quaesita exhibited significant antihyperglycemic activity in diabetic rats.

- Garcinol has significantly higher antihyperglycemic activity than its respective crude extracts.

- Dried fruits of G. quaesita and garcinol are potential drug leads for therapy of diabetes mellitus. 


\title{
RESEARCH ARTICLE
}

\section{Antihyperglycemic activity of fruit extracts of Sri Lankan endemic species Garcinia quaesita Pierre "Rathgoraka" and its isolated compound, garcinol}

\author{
D.S.N.K. Liyanagamage ${ }^{1}$, S. Jayasinghe ${ }^{1, *}$, A.P. Attanayake ${ }^{2}$, V. Karunaratne ${ }^{1}$ and D.S.A.Wijesundara ${ }^{3}$ \\ ${ }^{1}$ Department of Chemistry, Faculty of Science, University of Peradeniya, Peradeniya, Sri Lanka. \\ ${ }^{2}$ Department of Biochemistry, Faculty of Medicine, University of Ruhuna, Galle, Sri Lanka. \\ ${ }^{3}$ National Institute of Fundamental Studies, Hantana Road, Kandy, Sri Lanka.
}

Received: 14/04/2020 ; Accepted: 18/07/2020

\begin{abstract}
The dried fruit of Garcinia quaesita Pierre (Clusiaceae), is a well-known endemic spice in Sri Lanka and has been documented in traditional medicine as an antidiabetic agent. The antihyperglycemic effect of cold water, hot water, water : acetone fruit extracts of G. quaesita and its isolated compound, garcinol in streptozotocin-induced diabetic rats was studied. The percentage improvements of glucose tolerance upon total area under the oral glucose tolerance curve in cold water, hot water and water:acetone extracts of G. quaesita $(1.0 \mathrm{~g} / \mathrm{kg})$ were $6.2 \%$, $7.4 \%$ and $8.1 \%$, respectively. The isolated compound, garcinol at the three selected doses $(10 \mathrm{mg} / \mathrm{kg}, 20 \mathrm{mg} / \mathrm{kg}, 30 \mathrm{mg} / \mathrm{kg})$, showed a dose dependent, antihyperglycemic activity of $23.6 \%, 26.5$ $\%, 31.1 \%$ respectively compared to glibenclamide $(0.5 \mathrm{mg} / \mathrm{kg})$ $(36.1 \%)(p<0.05)$. The selected extracts of G. quaesita exhibited significant antihyperglycemic activity in streptozotocin-induced diabetic rats. The isolated compound, garcinol has significantly higher antihyperglycemic activity than the respective crude extracts. Accordingly, endemic dried fruits of G. quaesita and its isolated compound garcinol are promising antihyperglycemic agents and /or drug leads that would be beneficial in the management of diabetes mellitus.
\end{abstract}

Keywords: Garcinia quaesita; Garcinol; Antihyperglycemic effect; Hot water extract; Water: acetone extract.

\section{INTRODUCTION}

Diabetes mellitus has become a devastating epidemic and millions of people are continuously finding ways to manage diabetes worldwide. Diabetes is an endocrine disorder which occurs as a result of the inability of the pancreas to secrete insulin or defects in insulin action or both (American Diabetic Association, 2020). All types of diabetes are characterized by hyperglycemia which leads to development of diabetic specific vascular complications as retinopathy, nephropathy and neuropathy (Chawla et al., 2016). The hyperglycemia induced oxidative stress is considered as a key factor in the progression of diabetes and in the development of its complications. Furthermore, hyperglycemia-induced oxidative stress is correlated with elevated endothelial cell apoptosis in vivo (Li et al., 2017). The management of diabetes has progressed from monotherapy using insulin, insulin secretagogues, or combination therapy using insulin/insulin secretagogues with sensitizers and/or incretin-based treatments together with antioxidant supplements (Chaudhury et al., 2017).

Importantly, antidiabetic therapeutics with potent antioxidant potential has become apparent as a new strategy to arrest the progression of diabetes and its complications. In this regard, isolated antidiabetic compounds from medicinal plants with strong antioxidant and antihyperglycemic activity seem effective candidates to develop novel antidiabetic therapeutics with dual potentials of antihyperglycemic and antioxidant in the prevention of diabetes and its related complications.

Medicinal plants have gained tremendous interest as edible natural antihyperglycemic and antioxidant sources (Ganesan and $\mathrm{Xu}, 2019$ ). Some of the bioactive compounds isolated from these medicinal plants demonstrated hypoglycemic along with antioxidative properties in vivo and have been recommended to be effective in the long term management of diabetes and its complications (Salehi et al., 2019). Medicinal plants belonging to genus Garcinia have received great attraction worldwide and fruit extracts of Garcinia cambogia and Garcinia quaesita have become outstanding ingredients as weight reducing agents at present (Chuah et al., 2013). They have also been extensively used in Asian countries as a flavoring agent as well as a condiment in traditional cooking recipes (Liyanagamage et al., 2020). Garcinia quaesita Pierre (Clusiaceae), is an endemic plant to Sri Lanka and locally known as "Rathgoraka" in Sinhala (Figure 1)

Applications of dried fruit rinds of G.quaesita are well documented in traditional medicine as an astringent and antiseptic; internally, it is reported to act as a stomachic and is used in anorexia, chronic dyspepsia, hypertension and dyslipidemia (Jayaweera, 1980). Recent investigations in our laboratory have revealed that non polar extracts of dried fruit rinds of $G$. quaesita possess incredible antioxidant activity than the powerful antioxidant, ascorbic acid (Liyanagamage et al., 2020). Interestingly, isolated compound, garcinol from G.quaesita exhibited more than ten fold antioxidant capacity compared to ascorbic acid (Liyanagamage et al., 2020). Further, several studies were reported for the antidiabetic activity of the many plant species of the genus Garcinia as well as for garcinol (Padhye et al., 


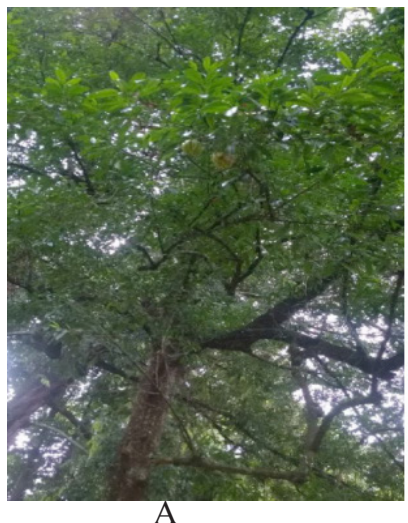

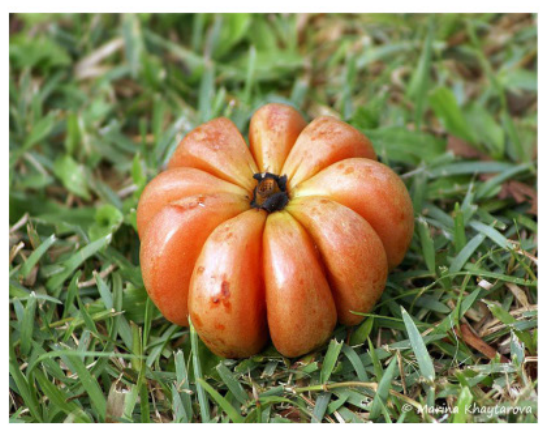

B

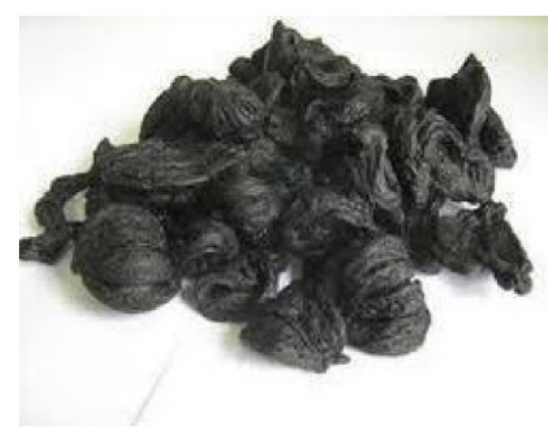

$\mathrm{C}$

Figure 1: Tree of Garcinia quaesita (A), ripe fruit of Garcinia quaesita (B), dried fruit rinds of Garcinia quaesita (C).

2009; Payamalle et al., 2017; Ali et al., 2017; Chen et al., 2019). However, the antidiabetic potential of the Sri Lankan species, G. quaesita, has not been investigated to date. Hence, we conducted the present study to investigate the acute antihyperglycemic activity of fruit extracts of G. quaesita and the isolated compound, garcinol in streptozotocin induced diabetic rats.

\section{MATERIALS AND METHODS}

\section{General Procedure}

Streptozotocin (STZ) was purchased from MP Biomedicals, France. Glucose-oxidase enzyme assay kit was purchased from Stanbio, USA. All chemicals and solvents were analytical grade and used without further purification. The biochemical parameters were estimated using UVVisible spectrophotometer (Gallenkamp PLC, UK). ${ }_{1} \mathrm{H}$ and ${ }_{13} \mathrm{C}$ NMR spectra were recorded on $400 \mathrm{~Hz}$ NMR (Bruker, USA) using $\mathrm{CDCl}_{3}$. Melting points of the isolated compounds were determined using a Stuart scientific electro-thermal melting point apparatus and reported without correction. FT-IR spectral data were recorded in a FT-IR Spectrophotometer (Shimadzu, Japan) on $\mathrm{KBr}$ pellets. A rotatory evaporator (Buchi, Switzerland) was used in the preparation of plant extracts.

\section{Plant materials}

The dried fruit rinds of $G$. quaesita were collected from Kandy, Central Province, Sri Lanka in March 2016. The plant itself was taxonomically authenticated by comparing specimens at the National Herbarium, National Botanical Gardens, Peradeniya, Sri Lanka. A voucher specimen (No: 6/01/H/03) was deposited at National Herbarium, National Botanical Garden, Peradeniya, Sri Lanka.

\section{Preparation of plant extracts}

The dried fruit rinds of $G$. quaesita were washed immediately with running water. Once the sample was dried, equal amounts (500 g each) of powdered samples were extracted into hexane, cold water and water:acetone mixture (1:1) separately using a bottle shaker at room temperature $\left(150 \mathrm{rpm}, 27^{\circ} \mathrm{C}\right)$. Further, a hot water extract was prepared by refluxing $50 \mathrm{~g}$ of dried fruits in $400 \mathrm{~mL}$ of water for three hours. All extracts were concentrated using a rotary evaporator at low temperature and were further dried by freeze drying to obtain a fine powder of each extract mixture.

\section{Isolation of antioxidant compound, garcinol}

Garcinol was isolated from fhe hexane extract of fruits of G. quaesita using bioassay guided fractionation with DPPH assay and the structure was elucidated by comparing with reported data in the previous study (Liyanagamge et al., 2020). The same sample isolated was used in the present in-vivo studies as well.

\section{Ethical considerations in laboratory animals}

All animal protocols in experiments and their maintenance were carried out according to the $3 \mathrm{R}$ principle of replacement, reduction and refinement involving accepted animal ethics. Minimum required numbers of animals were allocated to a particular group and all efforts were undertaken to minimize the suffering of animals. Ethical clearance for the animal study was approved by the Ethical Review Committee of Faculty of Medicine, University of Ruhuna, Sri Lanka (09.03.2016.3.8).

\section{Animals}

Adult male Wistar rats (body weight: $225 \pm 20 \mathrm{~g}, 10$ 12 weeks) were obtained from the Medical Research Institute (MRI), Colombo, Sri Lanka. The animals were accommodated in an Animal Research Facility Centre, Faculty of Medicine, University of Ruhuna, Sri Lanka. Animals were retained at approximate $12 \mathrm{~h} / 12 \mathrm{~h}$ of light and dark cycles, at a temperature of $26{ }^{\circ} \mathrm{C}$. Pelleted food and water were given ad libitum. Adult male Wistar rats were allowed to acclimatize for a period of two weeks prior to be used them in experiments. Oral feeding was performed using a stainless steel gavage (Straight, 10 Gauge, 5.9 inches $(15.2 \mathrm{~cm}$ ) length, $6.4 \mathrm{~mm}$ tip). A volume of $0.5 \mathrm{~mL}$ blood was collected from the tail tip of the animal for oral glucose tolerance test under mild anesthesia using anesthetic ether. Animals were handled by trained research and technical staff. 


\section{Induction of diabetes mellitus in Wistar rats}

The animals were fasted for $10 \mathrm{~h}$ and streptozotocin (STZ) dissolved in $0.1 \mathrm{M}$ citric acid/sodium citrate buffer, $\mathrm{pH}$ 4.5 at a dose of $70 \mathrm{mg} / \mathrm{kg}$ was injected intraperitoneally (Eidi et al., 2006). After $72 \mathrm{~h}$ of administration of STZ, the fasting serum glucose (FSG) concentration of all animals was estimated using a commercially available assay kit using the glucose-oxidase method (Yuen and McNeill, 2000). The rats with an FSG of $>11.1 \mathrm{mmol} / \mathrm{L}$ were regarded as hyperglycemic and were used in experiments (Kumar et al., 2012).

\section{Acute antihyperglycemic activity of fruits extracts of G. quaesita in diabetic rats}

Male Wistar rats were divided into seven groups. Group one ( $n=6 /$ group) and two ( $n=6 /$ group) served as the healthy and diabetic control groups, respectively and received distilled water. Groups three, four and five served as plant extracts treated diabetic rats and received cold water, hot water and water:acetone extracts of fruits of G. quaesita at the therapeutic dose at $1.0 \mathrm{~g} / \mathrm{kg}$ orally. Glibenclamide $(0.5 \mathrm{mg} / \mathrm{kg})$ as the positive control was administered to diabetic rats in the sixth group ( $n=6 /$ group).

\section{Acute antihyperglycemic activity of the isolated compound (garcinol) in diabetic rats}

Adult male Wistar rats were allocated into six groups and group one and two considered as untreated healthy ( $n=6 /$ group) and diabetic control ( $\mathrm{n}=6 /$ group) rats, respectively. Both groups of rats received distilled water. The isolated compound, garcinol was administered orally to diabetic rats ( $n=6$ / group) in groups three, four and five, at different doses of $10 \mathrm{mg} / \mathrm{kg}, 20 \mathrm{mg} / \mathrm{kg}$ and $30 \mathrm{mg} / \mathrm{kg}$, respectively. The diabetic rats in the sixth group ( $n=6 /$ group) which was considered as the positive control group received the standard antidiabetic drug, glibenclamide $(0.5 \mathrm{mg} / \mathrm{kg})$.

Wistar rats of all the test groups were given an oral dose of glucose $(3.00 \mathrm{~g} / \mathrm{kg}), 30 \mathrm{~min}$ after the administration of the extract/isolated compound/glibenclamide. The acute antihyperglycemic effect was evaluated over a four hour period using total area under the curve (TAUC) method (Purves, 1992). The results of the test group rats were compared with the diabetic untreated control rats.

\section{Statistical analysis}

Statistical analysis was performed using ANOVA followed by Dennett's multiple comparison test in determination of acute antihyperglycemic activity in diabetic rats. Statistical significance was considered at $\mathrm{p}<0.05$.

\section{RESULTS AND DISCUSSION}

The garcinol was isolated from the hexane extract of G. quaesita as reported (Liyanagamge et al., 2020). Acute screening of antihyperglycemic activity using oral glucose tolerance test in experimental diabetic animals is imperative as a preliminary investigation prior to the conduct long term investigations in vivo. This provides sufficient and reliable initial screening data on the potency of antihyperglycemic effects in different extracts at different doses. Indeed, screening of glucose tolerance provides rapid and convenient information in an inexpensive way adhering to ethical concerns with minimum pain to animals with a limited quantity of the test sample (crude extracts/ isolated compounds). In the present study, we used the streptozotocin induced diabetic rat model to screen different extracts of G. quaesita and its isolated compound, garcinol.

Streptozotocin-induced diabetic rats were orally administered with cold water, hot water and water:acetone extracts of fruits of $G$. quaesita $(1.0 \mathrm{~g} / \mathrm{kg})$. The effect of the therapeutic dose of the each extract of G. quaesita on fasting blood glucose concentration is presented in Table 1. The oral administration of cold water, hot water and water: acetone extracts of $G$. quaesita at the equivalent human therapeutic dose and glibenclamide $(0.5 \mathrm{~g} / \mathrm{kg})$ lowered the serum glucose concentration significantly throughout the four hour period in the oral glucose tolerance test in diabetic rats $(\mathrm{p}<0.05)$.

The total values of area under the oral glucose tolerance curve (TAUC) values of cold water, hot water and water:acetone extracts of fruits of G. quaesita and glibenclamide treated diabetic rats are shown in Figure 2. The cold water, hot water and water:acetone extracts of $G$. quaesita showed a statistically significant improvement of oral glucose tolerance at the therapeutic dose $(1.0 \mathrm{~g} / \mathrm{kg})$ $(p<0.05)$. The total area under oral glucose tolerance curve was used to evaluate the degree of reduction in blood glucose concentration on glucose tolerance over a period of four hours with the extract of G. quaesita. The reduction in total area under the curve reflects high efficacy or improvement in glucose tolerance in the plant extract treated group. The oral glucose tolerance was limited to four hours due to a restriction of fasting period in experimental animals.

Percentages improvement in cold water, hot water and water:acetone extracts of G. quaesita were $6.2 \%, 7.4 \%$ and $8.1 \%$ in glucose tolerance, respectively. Oral administration of water: acetone extract showed the highest percentage of improvement of $5.0 \%$ in antihyperglycemic activity at its therapeutic dose, whereas glibenclamide treated rats showed an improvement of $36.1 \%$ in glucose tolerance in streptozotocin induced diabetic rats. Water: acetone mixture is in a polar and semi polar form and contains a complex mixture of polar and semi polar compounds which might have led to the highest activity. Significant antihyperglycemic activity of hot water extract corroborates with their usage in traditional Ayurvedic decoctions. In addition, dried fruit rinds of $G$. quaesita flavoured curry preparations offer an antidiabetic source to manage hyperglycemia in diabetic patients. Based on the results, acute antihyperglycemic effect of the most active water:acetone extract was not statistically comparable to the acute antihyperglycemic effects of glibenclamide $(\mathrm{p}>0.05)$. Generally, it is obvious that a crude extract probably would not reach to a level of a pure antidiabetic drug as glibenclamide. Glibenclamide lowers the blood glucose levels by stimulating insulin secretion through a direct secretory effect on the pancreatic $\beta$-cells (Riefflin et al., 2015). However, it is unrealistic to expect a comparable antihyperglycemic effect as glibenclamide from most of the crude plant extracts. 
Table 1: The effect of fruit extracts of G. quaesita on serum glucose concentration in diabetic rats.

\begin{tabular}{lllllll}
\hline Group & \multicolumn{7}{l}{ Serum glucose concentration values in OGTT (mmol) } \\
\hline & Fasting & $1 / 2 \mathrm{~h}$ & $1 \mathrm{~h}$ & $2 \mathrm{~h}$ & $3 \mathrm{~h}$ & $4 \mathrm{~h}$ \\
Healthy control rats & $5.00 \pm 0.28$ & $9.05 \pm 0.27$ & $6.95 \pm 0.21$ & $6.16 \pm 0.42$ & $4.98 \pm 0.10$ & $4.17 \pm 0.10$ \\
Diabetic control rats & $12.92 \pm 0.29$ & $17.13 \pm 0.40$ & $15.68 \pm 0.39$ & $14.59 \pm 0.10$ & $13.29 \pm 0.20$ & $12.33 \pm 0.28$ \\
Diabetic + Cold water & $13.17 \pm 0.16$ & $16.35 \pm 0.10$ a & $14.83 \pm 0.12$ a & $14.24 \pm 0.17$ a & $13.66 \pm 0.19$ & $13.23 \pm 0.07$ a \\
Diabetic + Hot water & $12.77 \pm 0.26$ & $16.06 \pm 0.14$ a & $14.82 \pm 0.16$ a & $13.43 \pm 0.18$ a & $13.01 \pm 0.24$ a & $12.26 \pm 0.14$ a \\
Diabetic+ Water:acetone & $12.52 \pm 0.10$ & $15.73 \pm 0.08$ a & $14.37 \pm 0.15$ a & $13.53 \pm 0.19$ a & $13.00 \pm 0.17$ a & $12.28 \pm 0.15$ a \\
Diabetic+Glibenclamide & $12.34 \pm 0.30$ & $16.30 \pm 0.39$ a & $11.19 \pm 0.21$ a & $7.44 \pm 0.31$ a & $6.79 \pm 0.17$ a & $5.80 \pm 0.07$ a \\
\hline
\end{tabular}

The values are expressed as mean \pm SEM ( $n=6$ /group). Data were analyzed by ANOVA followed by Dunnett's test $(\mathrm{p}<0.05)$.aP $<0.05$ when compared with corresponding values of the diabetic control group.

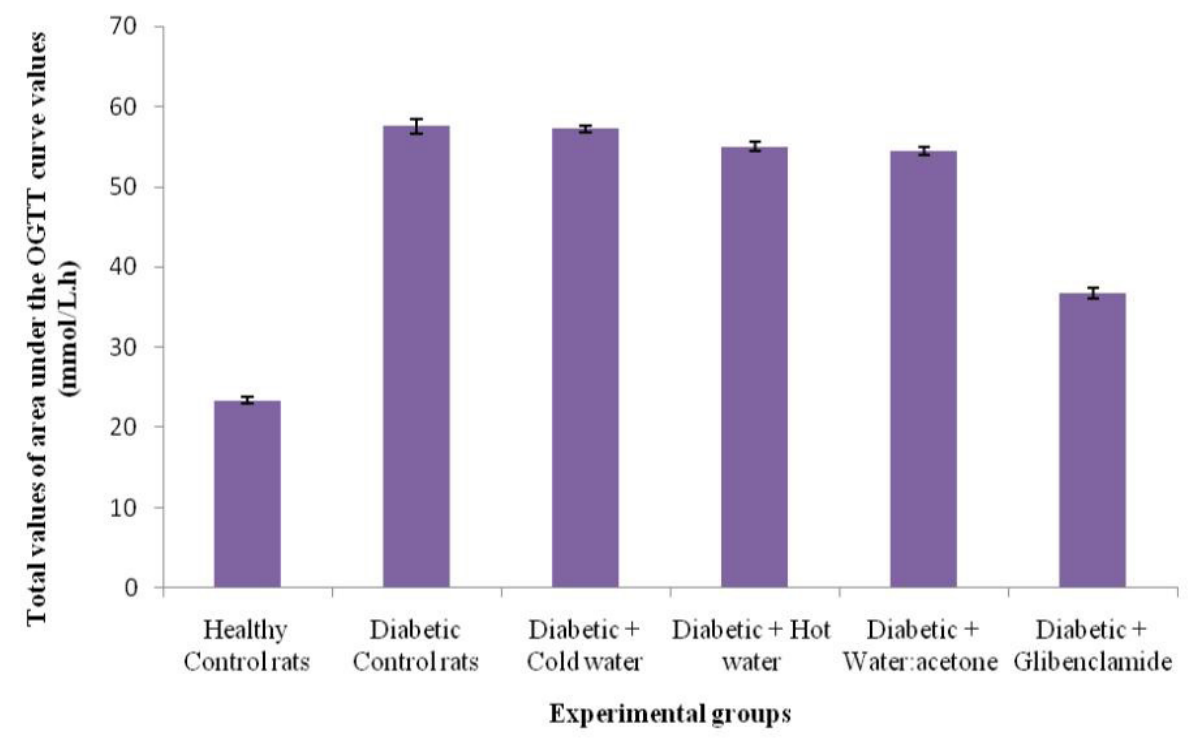

Figure 2: The effect of fruit extracts of G. quaesita total values of area under the OGTT curve values.

The results of our present study agreed with the findings made by Khatib and Patil (2011), who reported that the acute antihyperglycemic activity of the whole fruit extracts of $G$. indica, one of species in the genus Garcinia, closely related to G. quaesita morphologically. The oral administration of the aqueous extract of fruits of $G$. indica showed a significant reduction in blood glucose concentration between 30 to 120 minutes in both streptozotocin induced diabetic rats $(\mathrm{p}<0.001)$. Moreover, reports by Yamaguchi et al., (2000), Shetty and Pushpa (2018) and Deore et al., (2018) revealed that the fruit extract of $G$. indica significantly lowered the fasting blood glucose concentration in hyperglycemic rats in a long term study. Further, long term antihyperglycemic effects were reported based on Garcinia species such as G. cambogia, G. mangostana in diabetic animal models (Watanabe et al., 2018). Even though the present study was did not ilucidate the exact antidiabetic mechanisms of fruits of $G$. quaesita, we propose that the fruits of G. quaesita would lead to potent antidiabetic activity in a long term study most probably through an insulin-like activity same as other species of the genus Garcinia.

Garcinol is a tri-isoprenylatedchalcone and is considered as a potent antioxidant compound which has numerous health benefits (Padhye et al., 2009). Garcinol was isolated from G. quaesita in a yield of $3.67 \%$ (Figure 3).

The results of serum glucose concentration of test animals during four hours in garcinol treated animals are summarized in Table 2. The treatment with garcinol (10 $\mathrm{mg} / \mathrm{kg}, 20 \mathrm{mg} / \mathrm{kg}, 30 \mathrm{mg} / \mathrm{kg}$ ) shows a significant dose dependent acute antihyperglycemic effect on the glucose tolerance in streptozotocin induced diabetic rats.

According to the results in Table 2, diabetic rats treated with 20 and $30 \mathrm{mg} / \mathrm{kg}$ of garcinol showed a statistically significant reduction in blood glucose concentration after $1 / 2 \mathrm{~h}$ compared to diabetic control rats. More importantly, the acute antihyperglycemic effect of glibenclamide $(0.5$ $\mathrm{mg} / \mathrm{kg}$ ) was comparable to the effect of garcinol even at the dose of $10 \mathrm{mg} / \mathrm{kg}$ in diabetic rats.

The total values of area under the oral glucose tolerance curve (TAUC) values of garcinol and glibenclamide treated diabetic rats are shown in Figure 4. The administration of garcinol at three selected doses and glibenclamide caused a gradual decrease in the TAUC values as $23.6 \%, 26.5$ $\%, 31.1 \%$ and $36.1 \%$ with those of diabetic control rats as observed up to four hours after the treatment, 


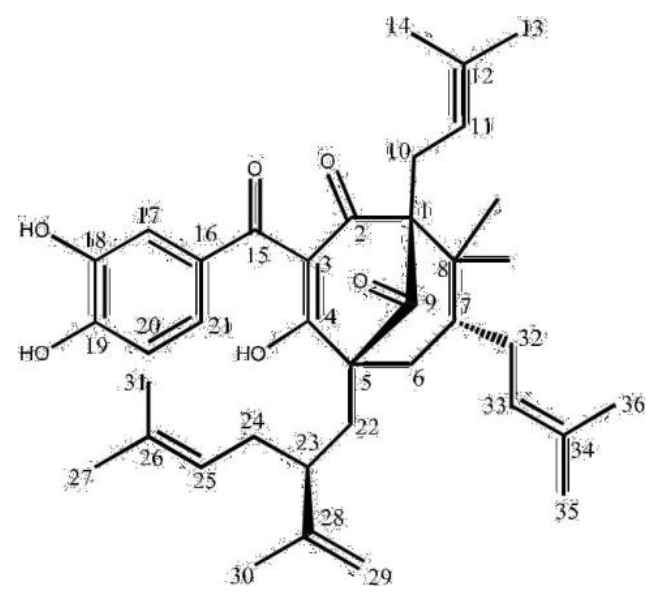

Figure 3: Structure of garcinol.

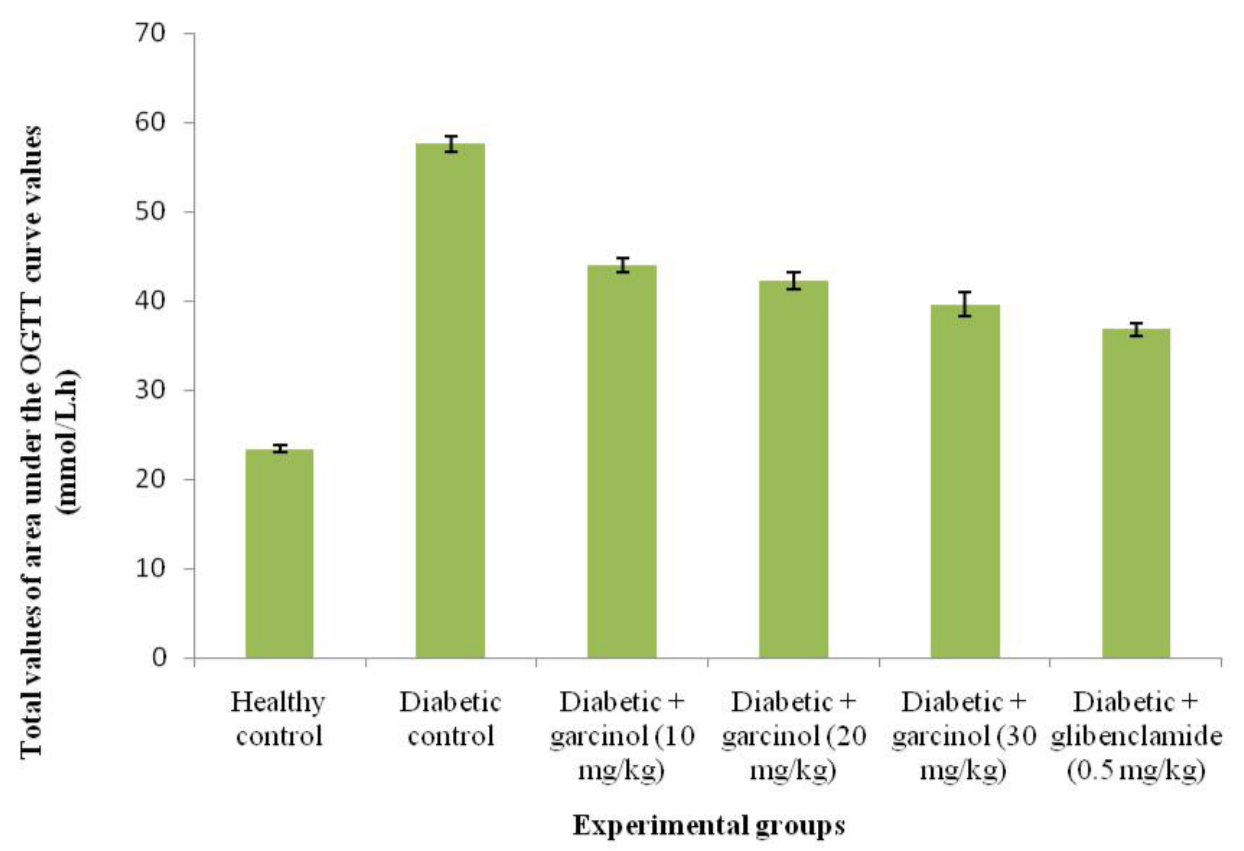

Figure 4: Effect of garcinol on total values of area under the OGTT curve values.

Table 2: Effect of garcinol on oral glucose tolerance in streptozotocin induced diabetic rats.

\begin{tabular}{|c|c|c|c|c|c|}
\hline \multirow[t]{2}{*}{ Group } & \multicolumn{5}{|c|}{ Serum glucose concentration $(\mathrm{mmol} / \mathrm{L})$} \\
\hline & FSG & $1 / 2 \mathrm{~h}$ & $1 \mathrm{~h}$ & $2 \mathrm{~h}$ & $4 \mathrm{~h}$ \\
\hline Healthy Control & $5.06 \pm 0.13$ & $8.70 \pm 0.25$ & $6.65 \pm 0.15$ & $5.54 \pm 0.16$ & $5.00 \pm 0.164 .22 \pm 0.12$ \\
\hline Diabetic Control & $12.92 \pm 0.29$ & $17.13 \pm 0.40$ & $15.68 \pm 0.39$ & $14.52 \pm 0.10$ & $13.29 \pm 0.2012 .33 \pm 0.28$ \\
\hline Diabetic+ Garcinol(10 mg/ kg) & $12.78 \pm 0.13$ & $16.46 \pm 0.27 \mathrm{~b}$ & $12.10 \pm 0.53 \mathrm{ab}$ & $10.63 \pm 0.34$ a & $9.10 \pm 0.21$ a $\quad 8.26 \pm 0.31 \mathrm{a}$ \\
\hline Diabetic+ Garcinol(20 mg/ kg) & $12.40 \pm 0.53$ & $15.89 \pm 0.29 \mathrm{ab}$ & $10.80 \pm 0.32 \mathrm{ab}$ & $9.97 \pm 0.27$ a & $8.99 \pm 0.23$ a \\
\hline Diabetic+ Garcinol (30 mg/ kg) & $12.52 \pm 0.54$ & $15.92 \pm 0.37 \mathrm{ab}$ & $10.68 \pm 0.30_{\mathrm{ab}}$ & $8.62 \pm 0.15$ a & $8.52 \pm 0.26$ a $\quad 6.73 \pm 0.35$ a \\
\hline Diabetic+ Glebenclamide $(0.5$ mg/ kg) & $12.34 \pm 0.30$ & $16.30 \pm 0.39$ & $11.19 \pm 0.21 \mathrm{a}$ & $7.44 \pm 0.31 \mathrm{a}$ & $6.79 \pm 0.17 \mathrm{a}$ \\
\hline
\end{tabular}

The values are expressed as mean $\pm \operatorname{SEM}\left(n=6 /\right.$ group). Data were analyzed by ANOVA followed by Dunnett's test $(\mathrm{p}<0.05)$. ${ }^{\mathrm{a}} \mathrm{p}<0.05$ when compared with the corresponding values. ${ }^{b} \mathrm{P}>0.05$ when compared with corresponding values of the glibenclamide. 
respectively. Mali and co-workers (2017) have performed a histopathological study of the pancreas in streptozotocin induced diabetic rats after administration of garcinol revealing the regeneration effect of garcinol on pancreatic $\beta$ cells. Furthermore, the results of the present investigation reconfirmed the antidiabetic properties of garcinol and provided supportive data for its beneficial effects against hyperglycemia. The scrutinization data presented in this paper would be useful and valuable in carrying out the long term investigations on the most active extract of $G$. quaesita.

\section{CONCLUSIONS}

The above results revealed that hot water and water:acetone extracts of fruits of $G$. quaesita at the therapeutic dose $(1.00 \mathrm{~g} / \mathrm{kg})$ exhibited a significant antihyperglycemic activity in streptozotocin-induced diabetic rats. Bioactivity guided fractionation of fruits of $G$. quaesita led to the isolation of the potent bioactive compound, garcinol which showed a very significant reduction in oral glucose tolerance in streptozotocin-induced diabetic rats. The acute antihyperglycemic activity of garcinol (at the dose of 10 $\mathrm{mg} / \mathrm{kg})$ was comparable to the glibenclamide $(0.5 \mathrm{~g} / \mathrm{kg})$ in diabetic rats.

\section{Data Availability}

The data used to support the findings of this study are included within the article and the raw data also available upon request.

\section{DECLARATION OF CONFLICT OF INTEREST}

All authors declare having no conflict of interest.

\section{ACKNOWLEDGEMENT}

This work was supported by the University Research Grant, University of Peradeniya, Sri Lanka (B/Sc/2016/ $\mathrm{CH} / \mathrm{URG} / 52 / \mathrm{S})$.

\section{REFERENCES}

Ali, M., Paul, S., Tanvir, E.M., Hossen, M., Rumpa, N.E.N., Saha, M., Bhoumik, N.C., Islam, A., Hossain, M., Alam, N. and Gan, S.H. (2017). Antihyperglycemic, antidiabetic, and antioxidant effects of Garcinia pedunculata in rats. Evidence-Based Complementary and Alternative Medicine 2017. https://doi. org/10.1155/2017/2979760.

American Diabetes Association (2020). Classification and diagnosis of diabetes: standards of medical care in diabetes-2020. Diabetes care 43: 14-31. https://doi. org/10.2337/dc20-S002.

Chaudhury, A., Duvoor, C., Dendi, R., Sena, V., Kraleti, S., Chada, A., Ravilla, R., Marco, A., Shekhawat, N.S., Montales, M.T. and Kuriakose, K. (2017). Clinical review of antidiabetic drugs: implications for type 2 diabetes mellitus management. Frontiers in Endocrinology 8: 6. https://doi.org/10.3389/ fendo.2017.00006.

Chawla, A., Chawla, R. and Jaggi, S. (2016). Microvasular and macrovascular complications in diabetes mellitus: distinct or continuum? Indian Journal of
Endocrinology and Metabolism 20: 546. https://dx.doi. org/10.4103\%2F2230-8210.183480

Chen, T.H., Tsai, M.J., Fu, Y.S. and Wen.g, C.F. (2019). The exploration of natural compounds for anti-diabetes from distinctive species Garcinia linii with comprehensive review of the Garcinia family. Biomolecules 9: 641. https://dx.doi.org/10.3390\%2Fbiom9110641.

Chuah, L.O., Ho, W.Y., Beh, B.K. and Yeap, S.K. (2013). Updates on antiobesity effect of Garcinia origin (-)HCA. Evidence-Based Complementary and Alternative Medicine 2013. https://doi.org/10.1155/2013/751658.

Deore, A.B., Sapakal, V.D. and Naikwade, N.S. (2018). Antidiabetic, antihyperlipidemic and renal protective activities of Garcinia indica Linn. Clusiaceae. International Journal of Pharmaceutical Sciences and Drug Research 10: 39-45. https://doi.org/10.25004/ IJPSDR.2018.100107.

Eidi, A., Eidi, M. and Esmaeili, E. (2006). Antidiabetic effect of garlic (Allium sativum L.) in normal and streptozotocin-induced diabetic $r$ a $\mathrm{t}$ s . Phytomedicine 13: 624-629. https://doi.org/10.1016/j. phymed.2005.09.010.

Ganesan, K. and Xu, B. (2019). Anti-diabetic effects and mechanisms of dietary polysaccharides. Molecules 24: $556 . \quad$ https://dx.doi. org/10.3390\%2Fmolecules24142556.

Jayaweera, D.M.A. (1980). Medicinal plants (Indigenous and exotic) used in Ceylon. The national science council of Sri Lanka, Colombo, Sri Lanka 3: 67.

Khatib, N.A. and Patil, P.A. (2011). Evaluation of Garcina indicawhole fruit extracts for hypoglycemic potential in streptozotocin induced hyperglycemic rats. Research Journal of Pharmacy and Technology 4: 999-1003. http://www.indianjournals.com/ijor.a $\mathrm{t}=$ ijor:rjpt\&volume $=4 \&$ issue $=6$ \&article $=033$.

Kumar, S., Singh, R., Vasudeva, N. and Sharma, S. (2012). Acute and chronic animal models for the evaluation of anti-diabetic agents. Cardiovascular Diabetology 11: 9. https://dx.doi.org/10.1186\%2F1475-2840-11-9.

Li, Q., Lin, Y., Wang, S., Zhang, L. and Guo, L. (2017). GLP-1 inhibits high-glucose-induced oxidative injury of vascular endothelial cells. Scientific Reports 7: 1-9. https://doi.org/10.1038/s41598-017-06712-z.

Liyanagamage, D.S.N.K., Jayasinghe, S., Priyadarshani Attanayake, A. and Karunaratne, V. (2020). Correlation between antioxidant activity and the garcinol content released from fruit rinds of endemic Garcinia quaesita Pierre on different cooking conditions. Journal of Food Quality 2020. https://doi.org/10.1155/2020/7389714.

Mali, K.K., Dias, R.J., Havaldar, V.D. and Yadav, S.J. (2017). Antidiabetic effect of garcinol on streptozotocin-induced diabetic rats. Indian Journal of Pharmaceutical Sciences 79: 463-468. https://doi. org/10.4172/ pharmaceutical-sciences.1000250.

Padhye, S., Ahmad, A., Oswal, N. and Sarkar, F.H. (2009). Emerging role of garcinol, the antioxidant chalcone from Garcinia indica Choisy and its synthetic analogs. Journal of Hematology \&Oncology 2: 38. https:// dx.doi.org/10.1186\%2F1756-8722-2-38.

Payamalle, S., Joseph, K.S., Bijjaragi, S.C., Aware, C., 
Jadhav, J.P. and Murthy, H.N. (2017).Anti-diabetic activity of Garcinia xanthochymus seeds.Comparative Clinical Pathologym 26: 437-446. https://doi. org/10.1007/s00580-016-2396-9.

Purves, R.D. (1992). Bias and variance of extrapolated tails for area-under-the-curve (AUC) and area-under-themoment-curve (AUMC). Journal of Pharmacokinetics and Biopharmaceutics 20: 501-510. https://doi. org/10.1007/BF01061468.

Riefflin, A., Ayyagari, U., Manley, S.E., Holman, R.R. and Levy, J.C. (2015). The effect of glibenclamide on insulin secretion at normal glucose concentrations. Diabetologia 58: 43-49. https://doi.org/10.1007/ s00125-014-3399-1.

Salehi, B., Ata, A., V Anil Kumar, N., Sharopov, F., Ramírez-Alarcón, K., Ruiz-Ortega, A., Abdulmajid Ayatollahi, S., Valere Tsouh Fokou, P., Kobarfard, F., Amiruddin Zakaria, Z. and Iriti, M. (2019). Antidiabetic potential of medicinal plants and their active components. Biomolecules 9: 551. https://dx.doi. org/10.3390\%2Fbiom9100551.

Shetty, P. and Pushpa, V.H. (2018). Evaluation of the oral hypoglycemic activity of methanolic extract of Garcinia indica seeds in streptozotocin induced diabetic Albino rats. International Journal of Basic \& Clinical Pharmacology 7: 1147. http://dx.doi. org/10.18203/2319-2003.ijbcp20182097.

Watanabe, M., Gangitano, E., Francomano, D., Addessi, E., Toscano, R., Costantini, D., Tuccinardi, D., Mariani, S., Basciani, S., Spera, G. and Gnessi, L. (2018). Mangosteen extract shows a potent insulin sensitizing effect in obese female patients: a prospective randomized controlled pilot study. Nutrients 10: 586. https://dx.doi.org/10.3390\%2Fnu10050586.

Yamaguchi, F., Ariga, T., Yoshimura, Y. and Nakazawa, H. (2000). Antioxidative and anti-glycation activity of garcinol from Garcinia indica fruit rind. Journal of Agricultural and Food Chemistry 48: 180-185. https:// doi.org/10.1021/jf990845y.

Yuen, V.G. and McNeill, J.H. (2000).Comparison of the glucose oxidase method for glucose determination by manual assay and automated analyzer. Journal of Pharmacological and Toxicological Methods 44: 543546. https://doi.org/10.1016/S1056-8719(01)00117-4. 